\section{(6) OPEN ACCESS}

\title{
Heat stress does not exacerbate tennis-induced alterations in physical performance
}

\author{
Olivier Girard, Ryan J Christian, Sébastien Racinais, Julien D Périard
}

Athlete Health and

Performance Research Centre, ASPETAR, Qatar Orthopaedic and Sports Medicine Hospital, Doha, Qatar

\section{Correspondence to}

Dr Olivier Girard, AspetarQatar Orthopaedic and Sports Medicine Hospital, Research and Education Centre,

PO Box 29222, Doha, Qatar; olivier.girard@aspetar.com

Received 3 October 2013 Revised 14 January 2014 Accepted 17 January 2014

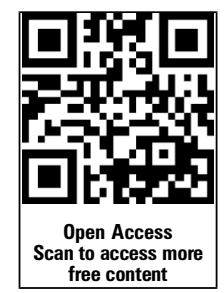

CrossMark

\footnotetext{
To cite: Girard 0 , Christian RJ, Racinais $S$, et al. Br J Sports Med 2014;48:i39-i44.
}

\begin{abstract}
Objectives To assess the time course of changes in physical performance in response to match-play tennis under heat stress.
\end{abstract}

Methods Two matches consisting of 20 min of effective playing time $(2 \times 10$ min segments) were played in $\mathrm{COOL}\left(\sim 102 \mathrm{~min} ; \sim 22^{\circ} \mathrm{C}\right.$ and $70 \%$ relative humidity $(\mathrm{RH}))$ and HOT $\left(\sim 119 \mathrm{~min} ; \sim 36^{\circ} \mathrm{C}\right.$ and $\left.35 \% \mathrm{RH}\right)$ environments. Repeated-sprint ability $(3 \times 15 \mathrm{~m}, 15 \mathrm{~s}$ rest), $15 \mathrm{~m}$ sprint time with a direction change $\left(180^{\circ}\right)$, vertical jump height (squat and countermovement jumps) and leg stiffness (multirebound jumps) were assessed in 12 competitive male players prematch, midmatch and postmatch, and 24 and $48 \mathrm{~h}$ after match completion. Results During the repeated-sprint ability test, initial $(+2.3 \%$ and $+3.1 \%)$ and cumulated sprint $(+1.5 \%$ and $+2.8 \%$ ) times increased from prematch to midmatch and postmatch, respectively $(p<0.001)$, while the sprint decrement score did not change. Match-play tennis induced a slowing (average of both conditions: $+1.1 \%$ and $+1.3 \%$ at midmatch and postmatch time points; $p=0.05$ ) of $15 \mathrm{~m}$ sprint time with direction change. Compared with prematch, leg stiffness $(-6.4 \%$ and $-6.5 \% ; p<0.001)$ and squat jump height $(-1.5 \%$ and $-2.4 \% ; p=0.05)$, but not countermovement jump height $(-0.7 \%$ and $-1.3 \%$; $\mathrm{p}>0.05)$, decreased midmatch and postmatch, respectively, regardless of the condition. Complete recovery in all physical performance markers occurred within $24 \mathrm{~h}$. Conclusions In tennis, match-related fatigue is characterised by impaired repeated-sprint ability, explosive power and leg stiffness at midmatch and postmatch, with values restored to prematch baseline $24 \mathrm{~h}$ into recovery. In addition, physical performance responses (match and recovery kinetics) are identical when competing in cool and hot environments.

\section{INTRODUCTION}

Over the course of a tennis match, players repeatedly execute forceful lower-limb actions to produce explosive strokes and rapid on-court movements (eg, accelerations, decelerations and multidirectional displacements). As the intensity and/or the duration of matches increase, these movements lead to exercise-induced fatigue, ${ }^{1-3}$ which can eventually be manifested as a decline of match-related physical performance. $^{4-6}$ In the coaching community, there is significant interest in assessing change of direction, (repeated) sprinting and/or jumping abilities with the prospect of identifying young and talented tennis players and/or evaluating the effects of various training and rehabilitation interventions.

Success in a tennis tournament requires winning several consecutive matches often separated by less than $24 \mathrm{~h}$, leaving limited time for full recovery before the next competitive event. With a modern game that is played with increasing physical demands, recovery of optimal musculoskeletal function for tennis play is vital to ensure optimal on-court performance, health and safety. Limited data exist concerning physical performance and recovery following one-off tennis matches, with assessments so far restricted to $90 \mathrm{~min}$ into the recovery period. ${ }^{4}$ When several matches are played (ie, tournament format), the available literature indicates that a $24-48 \mathrm{~h}$ recovery period may be sufficient for explosive power (ie, vertical jump ability tests) to recover. ${ }^{6} 8$ In an intermittent sport like football, complete recovery of physical performance markers (eg, jump ability, sprint speed) can take up to 96 h. ${ }^{9}$ To date, however, no studies have comprehensively documented the acute and delayed manifestations of match-related fatigue on tennis-specific running performance, including change-of-direction (COD) manoeuvres and repeated-sprint ability (RSA).

Playing tennis in hot ambient conditions for extended periods of time $(1-3 \mathrm{~h})$ increases the predisposition to exertional heat-illness, a potential health-threatening and performance-impairing condition, especially if fluid and electrolyte losses become excessive. $^{2} 10$ Despite the prevalence of this situation in competitive players during tennis practice and competition, ${ }^{10} 11$ the majority of tennis-related research has failed to explore the role of hyperthermia (ie, a state in which body core temperature is elevated $>38.5^{\circ} \mathrm{C}$ ) on physical performance. In one laboratory-based study, earlier and larger reductions in power output occurred during five, $15 \mathrm{~s}$ maximal efforts on a cycle ergometer when core and muscle temperature were elevated before the RSA test following the completion of a $40 \mathrm{~min}$ intermittent exercise bout leading to hyperthermia. ${ }^{12}$ Conversely, intermittent-sprint ${ }^{13}$ or repeated-sprint ${ }^{14}$ performance was not impaired in hot ambient conditions when athletes remained normothermic $\left(<38.5^{\circ} \mathrm{C}\right)$. Realistic field-based simulations are required to satisfy external validity, especially with regard to match-play tennis, since the severity of fatigue measures obtained after simulated-tennis activities are generally greater than during actual competition. ${ }^{15}$

The aim of this study was to assess the time course (prematch, midmatch, postmatch and $24 \mathrm{~h}$, $48 \mathrm{~h}$ into recovery) of changes in physical performance responses to match-play tennis in temperate and hot environments. It was hypothesised that the development of hyperthermia during match-play tennis in the heat would exacerbate fatigue-induced impairments in jumping and sprinting abilities and delay the recovery process, compared with a match undertaken in temperate conditions. 


\section{METHODS}

\section{Participants}

Twelve male players with an International Tennis Federation (ITF) number of 1-3 participated in the study. Mean age, height, body mass, weekly training volume and years of practice were $22.0 \pm 4.4$ years, $183.5 \pm 7.7 \mathrm{~cm}, 80.8 \pm 9.5 \mathrm{~kg}, 13.0 \pm 5.9 \mathrm{~h} /$ week and $16.4 \pm 3.6$ years, respectively. They played an average of $17 \pm 10$ tournaments and $65 \pm 23$ matches/year. They were informed of the study aims, requirements and risks before providing written informed consent.

\section{Study design}

Players completed two counter-balanced simulated matches on hard-court surfaces separated by $72 \mathrm{~h}$ or $144 \mathrm{~h}$. They were paired according to level of play and competed against the same opponent in each match. One match was played indoors in temperate conditions (COOL: $21.8 \pm 0.1^{\circ} \mathrm{C}$ air temperature, $72.3 \pm 3.2 \%$ relative humidity, $22.3 \pm 0.2^{\circ} \mathrm{C}$ globe temperature and $19.4 \pm 0.3^{\circ} \mathrm{C}$ Wet Bulb Globe Temperature (WBGT)) and the other outside in hot conditions (HOT: $36.8 \pm 1.5^{\circ} \mathrm{C}$ air temperature, $36.1 \pm 11.3 \%$ relative humidity, $47.5 \pm 3.5^{\circ} \mathrm{C}$ globe temperature and $33.6 \pm 0.9^{\circ} \mathrm{C}$ WBGT) under the sun. Wind velocity during the HOT matches was $0.7 \pm 0.2 \mathrm{~m} / \mathrm{s}$. The matches consisted of $20 \mathrm{~min}(2 \times 10 \mathrm{~min})$ of standardised effective playing time (ie, the proportion of match time spent in play) equivalent to $\sim 2 \mathrm{~h}$ total time or a typical threeset match. To calculate the effective playing time, each rally duration was measured with a stopwatch from the start (ie, ball leaving the hand of the serving player) to the end of the rally (ie, ball into the net or called out) and summed until the total duration reached 10 and $20 \mathrm{~min}$ (midmatch and postmatch, respectively). ${ }^{41617}$ First serve faults and double faults were not counted for point duration. One to three days prior to the start of the experiment, participants visited the testing and playing venue where they were thoroughly familiarised and accustomed to the performance test protocols. The coefficient of variation during three successive trials was $<2 \%$. During subsequent prematch testing sessions, if performance during sprinting or jumping efforts was $2.5 \%$ lower than the familiarisation session (eg, an increase in time in the first sprint of the repeated-sprint ability test), ${ }^{18}$ the test was immediately terminated and repeated after 2$3 \mathrm{~min}$ of rest (this occurred two times).

\section{Experimental protocol}

On arrival during match days (9:00h), participants voided and inserted a telemetric thermometer pill (VitalSense, Mini Mitter, Respironics, Herrsching, Germany) in the rectum (the length of a gloved index finger beyond the anal sphincter) for the measurement of core temperature. Body mass was measured to the nearest $0.1 \mathrm{~kg}$ before and after the matches using a calibrated balance (Seca 769, Hamburg, Germany). Details pertaining to the methods of these experimental procedures have been described elsewhere. ${ }^{19}$ In all experimental trials (prematch, midmatch, postmatch and $24 \mathrm{~h}$ and $48 \mathrm{~h}$ after the matches), the testing sessions were performed (ie, 3-5 min after midmatch and postmatch time points) in the HOT environment, directly on the tennis court in the same order (repeated-sprint ability, sprint time with COD, vertical jump height and leg stiffness). At baseline prematch and at 24 and $48 \mathrm{~h}$ postmatch, the testing session was preceded by a standardised warm-up. It consisted of $5 \mathrm{~min}$ of running at $9 \mathrm{~km} / \mathrm{h}$ on the indoor court, followed by $\sim 5$ min of athletic drills (ie, heel flicks, high knee runs, coordination skips and hopping), five progressive accelerations and two maximal $15 \mathrm{~m}$ sprints interspersed by 2 min of passive recovery on the outdoor court.

\section{Performance tests}

For the RSA and COD tests, time was measured using two photocells connected to an electronic timer and placed $1 \mathrm{~m}$ above the ground level (Polifemo Radio Light, Microgate, Bolzano, Italy). During the tests, the participants were verbally encouraged to produce maximal efforts.

\section{Repeated sprinting}

The participants underwent a RSA test consisting of three $15 \mathrm{~m}$ sprints departing every $15 \mathrm{~s}$. The sprints were performed in a back and forth format to allow for passive recovery during the short rest period. Participants had to complete the distance in a straight line alongside the tennis court as fast as possible. Three seconds prior to the start of each sprint, they were asked to assume the ready position and await the start signal. Each sprint was initiated from an individually chosen standing position, $50 \mathrm{~cm}$ behind the photocell gate, which started a digital timer. Three scores were calculated during the RSA test: the initial sprint time, the cumulated sprint time and the percent sprint decrement calculated as follows: $\{($ cumulated time $) /($ initial sprint time $\times 3)-1\} \times 100 .^{20}$

\section{Direction change sprint}

For the $15 \mathrm{~m}$ COD sprint assessment, markers were set at 0,5 and $10 \mathrm{~m}$ from the extended baseline alongside the tennis court. Participants ran from $0 \mathrm{~m}$ towards the centre of the court through the $10 \mathrm{~m}$ mark, turned (with the opportunity to slide) on the mark $\left(180^{\circ}\right)$ and ran back through the $5 \mathrm{~m}$ mark. Each player performed two trials interspersed by $1 \mathrm{~min}$ of passive recovery, and only the fastest time achieved was recorded.

\section{Vertical jumps}

Participants performed the following vertical jump tests with the hands kept on the hips to eliminate any influence of arm swing: (1) squat jump (SJ) starting from a static semisquatting position $\left(\sim 90^{\circ}\right.$ of flexion) maintained for $\sim 1 \mathrm{~s}$ and without any preliminary movement, (2) countermovement jump (CMJ) starting from a standing position, squatting down and then extending the knee in one continuous movement and (3) one set of multirebound jumps (MRJ) with rebounds to the highest possible point six times. For SJ and CMJ, participants were asked to perform two maximal trials and the highest jump was recorded. During MRJ, they were instructed to keep their knees as stiff as possible ('ankle jumps') and to have as brief a contact time as possible. Ground contact (MRJ) and flight times (SJ, CMJ and MRJ) were recorded using an optical measuring apparatus (Optojump, Microgate, Bolzano, Italy). From the flight times, jump height in the SJ and CMJ tests was calculated. ${ }^{21}$ From the flight and contact times, leg stiffness $(\mathrm{kN} / \mathrm{m})$ in the MRJ test was calculated. ${ }^{22}$

\section{Statistical analysis}

Values are expressed as means \pm SD. Two-way repeated-measures analysis of variance (ANOVAs) (Time (prematch, midmatch, postmatch, 24 vs $48 \mathrm{~h}$ postmatch) $\times$ condition (COOL vs HOT)) were used to compare physical performance data. ANOVA assumptions were verified preceding all statistical analyses; logarithmic transformations and Greenhouse-Geisser corrections were applied where appropriate. Pairwise differences were identified using the Bonferroni post hoc analysis procedure adjusted for multiple comparisons. All statistical calculations were performed using PASW software V.21.0 (SPSS, Chicago, Illinois, USA). The significance level was set at $\mathrm{p}<0.05$. 


\section{RESULTS}

\section{Match-play responses}

Match duration, the time to complete $20 \mathrm{~min}$ of effective play, was longer in the HOT $(119.2 \pm 9.6 \mathrm{~min})$ than in the COOL condition $(102.1 \pm 19.0 \mathrm{~min} ; \mathrm{p}<0.05)$. The increase in core temperature from start $\left(37.6 \pm 0.3\right.$ and $\left.37.5 \pm 0.3^{\circ} \mathrm{C}\right)$ to midmatch $\left(39.2 \pm 0.5\right.$ and $\left.38.6 \pm 0.1^{\circ} \mathrm{C}\right)$ and postmatch $(39.4 \pm 0.5$ and $\left.38.7 \pm 0.2^{\circ} \mathrm{C}\right)$ was greater in the HOT than in the COOL condition $(\mathrm{p}<0.05)$. A comprehensive description of thermal, physiological and perceptual responses has been presented in a companion paper. ${ }^{19}$ From prematch to postmatch, body mass loss was similar between conditions (COOL: $81.2 \pm 9.6$ to 80.9 $\pm 9.8 \mathrm{~kg}$ and HOT: $80.7 \pm 9.6$ to $80.2 \pm 10.3 \mathrm{~kg}$ ).

\section{Physical performance}

None of the physical performance variables displayed a main effect of condition or any significant interaction between time and condition. In the HOT and COOL conditions, sprinting
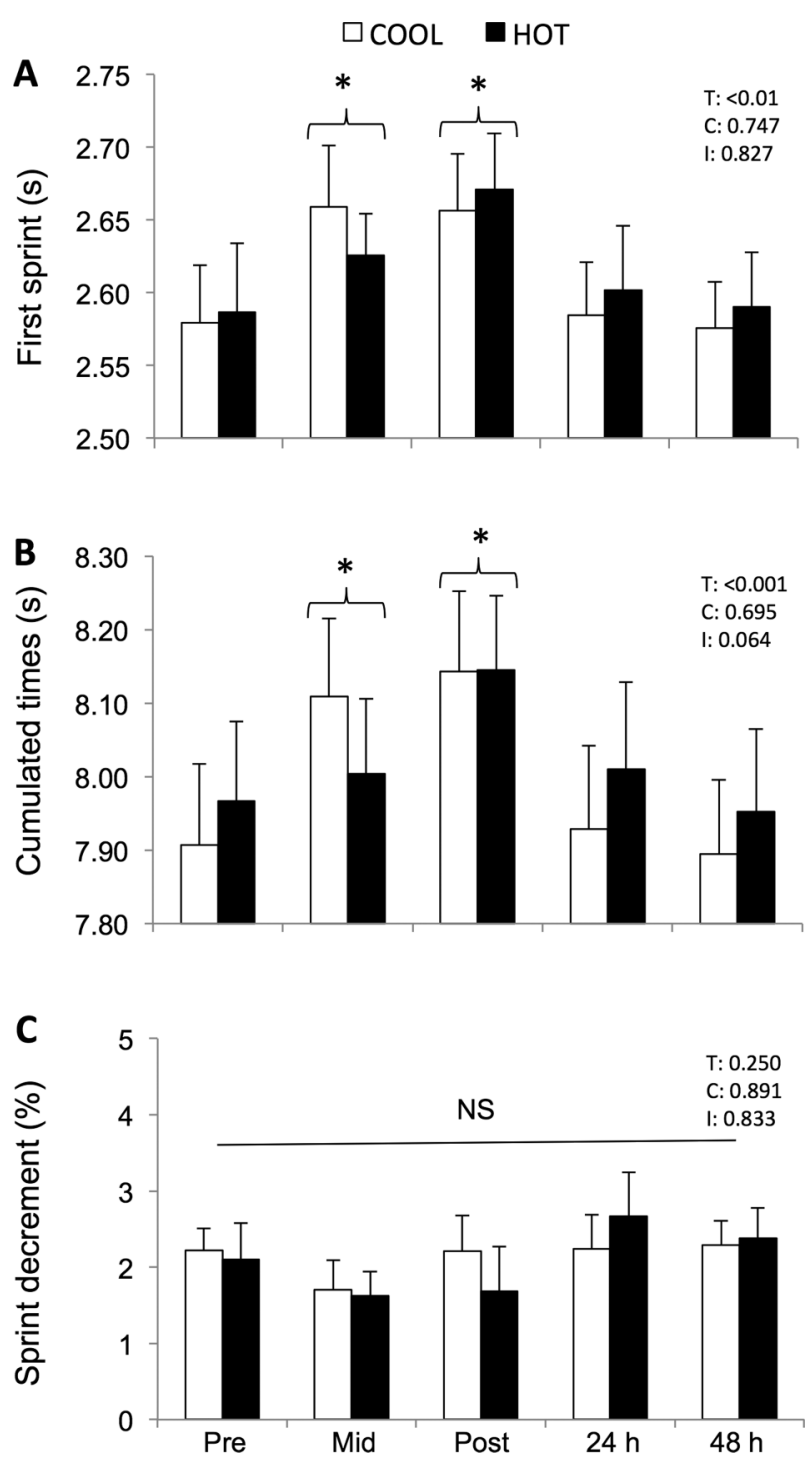

Figure 1 First sprint time (A), cumulated sprint times (B) and sprint decrement score $(C)$ during the repeated-sprint ability $(3 \times 15 \mathrm{~m}-15 \mathrm{~s}$ passive recovery) test. Measurements were taken prior to (Pre), during (Mid) and following (Post, 24 and 48 h) 20 min of effective match-play tennis in $\mathrm{COOL}$ and HOT conditions. T, C and I for time, condition and interaction effects. *Significantly different from Pre $p<0.05$. and jumping abilities returned to prematch levels within $24 \mathrm{~h}$ of recovery.

\section{Running tests}

During the RSA test, initial (average of both conditions: $+2.3 \%$ and $+3.1 \%$ ) and cumulated sprint (average of both conditions: $+1.5 \%$ and $+2.8 \%)$ times increased from prematch to midmatch and postmatch, respectively $(p<0.001)$, while the sprint decrement score did not change (figure 1). Match-play tennis induced a slowing (average of both conditions: $+1.1 \%$ and $+1.3 \%$ at midmatch and postmatch time points; $\mathrm{p}=0.05)$ of $15 \mathrm{~m}$ sprint time with COD (figure 2). The relative difference between straight-line and direction change in $15 \mathrm{~m}$ sprint times remained constant throughout the protocol (range: $133 \pm 2 \%$ $138 \pm 2 \% ; \mathrm{p}>0.05)$.

\section{Vertical jump tests}

Compared with prematch, SJ height (average of both conditions: $-1.5 \%$ and $-2.4 \% ; \mathrm{p}=0.05)$, but not $\mathrm{CMJ}$ height $(-0.7 \%$ and $-1.3 \%)$, decreased significantly midmatch and postmatch, irrespective of the condition (figure 3). Leg stiffness was similarly reduced midmatch and postmatch in both conditions compared with prematch (average of both conditions: $-6.4 \%$ and $-6.5 \% ; \mathrm{p}<0.001)$, with complete recovery within $24 \mathrm{~h}$ (figure 3).

\section{DISCUSSION}

To our knowledge, this is the first study directly comparing the acute and delayed (up to $48 \mathrm{~h}$ ) effects of $20 \mathrm{~min}$ of effective match-play tennis $(\sim 2 \mathrm{~h})$ in COOL versus HOT conditions on physical performance in high-standard players. Our results indicate that the physical performance parameters (ie, sprinting and jumping) associated with match-related fatigue were primarily impaired midmatch (ie, after $10 \mathrm{~min}$ of effective playing time) with limited additional reductions postmatch, and were fully recovered within $24 \mathrm{~h}$. Another novel finding was that the additional increase in core temperature noted in the HOT compared with the COOL match did not exacerbate the reduction in physical performance.

\section{Sprinting tests}

\section{Repeated sprinting ability}

RSA tests are used to assess team ${ }^{23-25}$ and racquet ${ }^{26}$ sport athletes' abilities to reproduce efforts at maximal intensity with limited recovery. Similar to recent football findings using a very

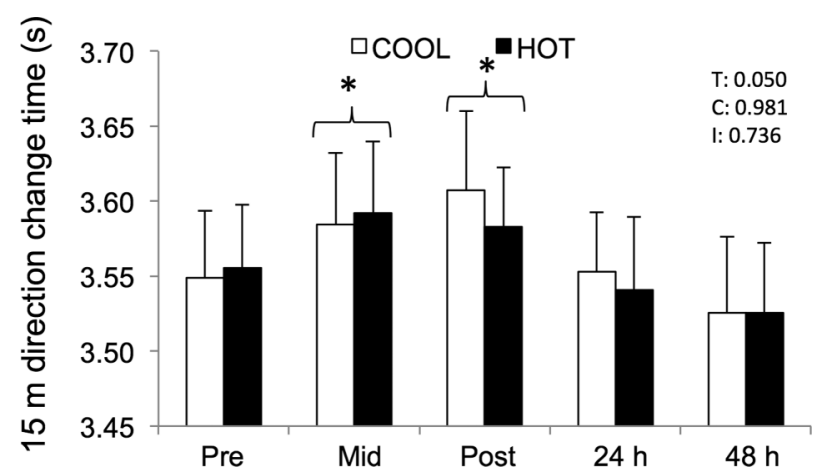

Figure 2 Sprint time during a $15 \mathrm{~m}$ sprint test with change of direction. Measurements were taken prior to (Pre), during (Mid) and following (Post, 24 and 48 h) 20 min of effective match-play tennis in $\mathrm{COOL}$ and HOT conditions. T, C and I for time, condition and interaction effects. *Significantly different from Pre $p<0.05$. 

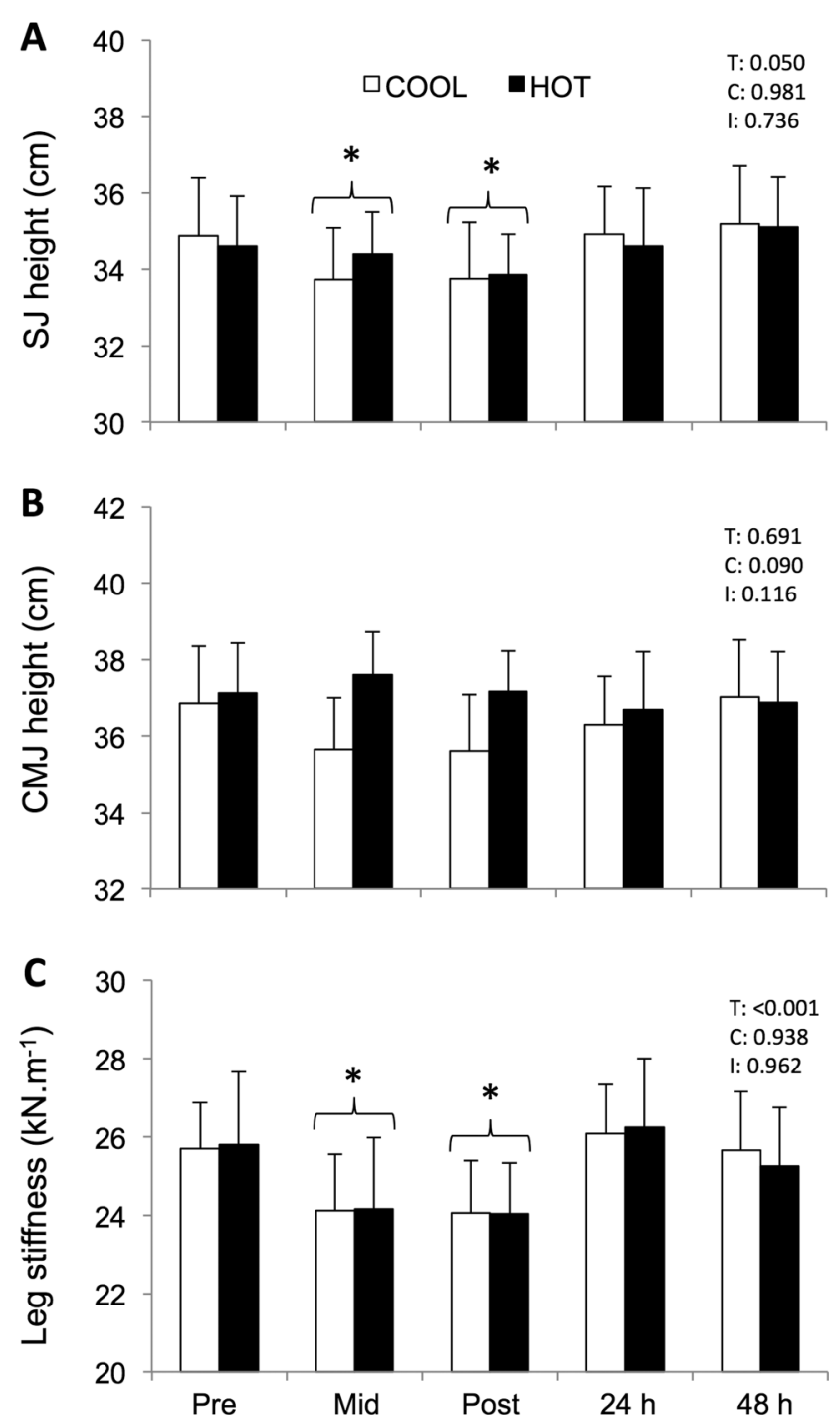

Figure 3 Squat jump height (A), countermovement jump height (B) and leg stiffness (C). Measurements were taken prior to (Pre), during (Mid) and following (Post, 24 and 48 h) 20 min of effective match-play tennis in COOL and HOT conditions. T, C and I for time, condition and interaction effects. *Significantly different from Pre, $\mathrm{p}<0.05$.

similar test format, ${ }^{25}$ our participants' RSA decreased comparably during the two matches (figure 1). The decrement observed is supported by the concurrently slower initial sprint time and longer cumulated sprint time to perform the RSA test postmatch, together with an unchanged sprint decrement. A possible explanation for the apparent match-induced decrease in RSA is an impairment in neuromuscular function, ${ }^{27}$ and in musculoskeletal compliance, in particular, a reduced ability to tolerate impact forces or stretch load after short exhaustive runs. ${ }^{28}$ In basketball players tested on a non-motorised treadmill before and immediately after an official match, impaired RSA $(6 \times 4-21 \mathrm{~s}$ of passive recovery) was associated with less efficient stride mechanics, which related to the specificity of the activities performed (eg, sprint, jump and shuffle frequencies). ${ }^{23}$ From a tennis perspective, a decrease in (repeated) sprint ability when fatigued may lengthen the time required to achieve whole body stability and control during stroke execution, which may be expected to cause less accurate or less powerful strokes and/or enhance error rate. ${ }^{29}$
Muscle soreness ${ }^{4}$ and serum creatine kinase levels, ${ }^{2}$ a marker of muscle damage, have been reported to increase in response to match-play tennis, remaining elevated for at least $24 \mathrm{~h}$ relative to resting levels. ${ }^{6}$ In the available tennis literature, there is no published data of the development and recovery of muscle damage markers from match-play tennis in a hot environment. In well-trained football players, neither markers of muscle damage nor recovery of repeated sprinting performance was aggravated by completing a competitive soccer match under heat stress, as compared with a control match (ie, same absolute duration: 90 min plus extratime) in a temperate environment. ${ }^{25}$ It was concluded that the muscle damage and subsequent slow recovery of match-related physical performance were related to exercise-induced factors, rather than heat-induced muscle injury. While substantial amounts of tissue disruption may have persisted $24-48 \mathrm{~h}$ into recovery (with or without intensified changes following the hot match) in the current test protocol (ie, strict control of the effective playing time, while total playing time was longer in the heat), there was no difference across trials and after $24 \mathrm{~h}$ of recovery, as RSA was similar to prematch.

\section{Direction changes}

In addition to elementary speed, on-court displacements with COD manoeuvres, often executed under pressure (ie, time constraints), represent key movement patterns in tennis. ${ }^{30}$ Following a $2 \mathrm{~h}$ strenuous training session, $70.5 \mathrm{~m}$ shuttle run time was increased by $\sim 0.5 \mathrm{~s} .{ }^{31}$ In the current study, $15 \mathrm{~m}$ sprint times $(\sim 0.05 \mathrm{~s})$ as well as COD times $(\sim 0.08 \mathrm{~s})$ increased during the matches, which, to our knowledge, is the first time that a reduced COD ability associated with tennis play has been demonstrated, regardless of environmental conditions (figure 2). Such an increase in time during a competitive match, although fractional, may represent the difference between a properly and improperly (ie, precipitated) executed groundstroke. When accelerating, the orientation of the total force applied to the ground is more important to sprint performance than its magnitude. ${ }^{32}$ As such, it may be argued that in addition to reductions in maximal or explosive strength per se (ie, reduced SJ height or leg stiffness, both in the vertical plane), a less efficient ground force application may have contributed to decrease linear sprinting and COD performances. This may be particularly true for high-speed COD movements, which require complex motor control and coordination (ie, mediolateral combined with braking and propulsive forces) between several muscle groups. Given the complexity of COD determinants, ${ }^{33}$ it has been argued that results reported for straight-line sprints may not be applicable to COD performances. ${ }^{34}$ Interestingly, however, following both matches, our data indicate that the impairment in $15 \mathrm{~m}$ linear sprint time was almost identical to that of the sprint with COD.

\section{Leg power tests}

Vertical jump height

Explosive power was evaluated using squat (concentric-only action) and countermovement (stretch-shortening cycle) jump tests (figure 3). Whether in COOL or HOT conditions, no effect of match-play tennis was found in CMJ performance. Similar CMJ results have previously been reported during prolonged match-play tennis $(>2 \mathrm{~h})$ in temperate conditions. ${ }^{4} 6$ Unchanged CMJ performance is possibly a consequence of movement reorganisation via compensatory strategies. However, because previous research has observed that inter-individual coordinative changes accompany fatiguing exercise, ${ }^{35}$ it 
is possible that some form of coordinative variability obscured mean changes across time. Consequently, future studies should determine how this might be brought about biomechanically.

In the current study, SJ performance was reduced as the match progressed. This may reflect a reduction of explosive strength in the lower limbs, as jumping ability with a longer active state (CMJ) was not distorted. ${ }^{36}$ This result corroborates those of Robineau $e t a l^{37}$ who reported that SJ height was reduced at halftime $(\sim 5 \%)$ and match-end $(\sim 8 \%)$, while CMJ was unaffected in eight amateurs performing a 90 min soccer game simulation. A novel finding of our study is that a $24 \mathrm{~h}$ period was long enough for the explosive attributes of leg extensor muscles to fully recover, irrespective of match conditions. In highly competitive National Collegiate Athletic Association (NCAA) Division 1 women tennis player, no physical performance fatigue (vertical jumps) lasting longer than $24 \mathrm{~h}$ was observed after 2 days of match-play. ${ }^{38}$ This indicates that brief explosiveness is compromised in response to matchplay tennis in HOT and COOL conditions, but that reorganisation strategies during movements with longer active states may compensate for this impairment.

\section{Leg stiffness}

At present, the optimal mechanical stiffness required for sport movements remains a topic of debate in the scientific community. ${ }^{33}$ Nonetheless, the leg stiffness values $(\sim 25 \mathrm{kN} / \mathrm{m})$ obtained in the current study are in the range of those previously reported $(18.2-27.5 \mathrm{kN} / \mathrm{m})$ in tennis players of different competitive standards. ${ }^{439}{ }^{40}$ It is generally accepted that the ability to produce and maintain 'optimal' levels of leg stiffness is beneficial for performance enhancement in explosive-type movements (eg, sprint running) ${ }^{41}$ and/or injury prevention (eg, increased joint stability). ${ }^{42}$ Interestingly, a positive correlation between leg stiffness and $20 \mathrm{~m}$ sprint performance in competitive players has previously been reported. ${ }^{43}$

In match-play tennis, decreased leg stiffness values may result in worse positioning to the ball and/or slower on-court movements during intense, successive rallies or as the match progresses. We have previously reported that leg stiffness progressively decreases throughout a $3 \mathrm{~h}$ tennis match in temperate conditions, with the decrement persisting 30 min into recovery. ${ }^{4}$ We now extend those findings by demonstrating that a period of $24 \mathrm{~h}$ is sufficient to fully recover leg stiffness values to prematch level; furthermore, that reductions in leg stiffness during match-play are not exacerbated by heat stress, despite the viscoelastic behaviour of the musculoskeletal complex being temperature-dependent (ie, higher temperatures increasing elasticity). ${ }^{44}$ Taken as a whole, our data indicate that competing under severe heat stress does not accentuate impairments in the mechanical characteristics of the muscle-tendon complex during prolonged match-play tennis.

\section{Additional considerations}

Competing under severe heat stress does not alter acute (match) or delayed (recovery dynamics) physical performance responses, despite a $\sim 0.7^{\circ} \mathrm{C}$ core temperature difference between conditions. Total fluid losses as small as $2 \%$ of body mass are associated with decrements in endurance-like performance. ${ }^{46}$ In tennis, a reduction in body mass $<3 \%$ is known to negatively affect 5 and $10 \mathrm{~m}$ sprint times after competing for $120 \mathrm{~min}$ in a warm environment $\left(\sim 31^{\circ} \mathrm{C}\right.$ and $\left.\sim 75 \% \mathrm{RH}\right) .^{7}$ However, in our study, dehydration levels remained relatively modest (ie, decrease in body mass $<1 \%$ ), ${ }^{19}$ highlighting that the typical in-match hydration habits of experienced tennis players were sufficient in minimising dehydration. Apart from the detrimental 'physical' effects that dehydration has on tennis players, their cognitive function, decision-making and proper execution of complex skills (ie, a global phenomenon known as 'perceptual' fatigue) can also be negatively affected. ${ }^{47} 48$ For example, technical proficiency has been suggested to suffer during closely contested or extended 3 -set to 5 -set matches in challenging ambient conditions (and correspondingly worsened hydration states). ${ }^{2}$ Therefore, testing the relationships between physical performance attributes and strokes proficiency in fatigued players competing in challenging environmental conditions deserves further investigation.

In this study, physical assessments were conducted in HOT outdoor conditions during which core and skin temperature were $\sim 38.5^{\circ} \mathrm{C}$ and $\sim 36^{\circ} \mathrm{C}(\mathrm{HOT})$ and $\sim 38.2^{\circ} \mathrm{C}$ and $\sim 33.5^{\circ} \mathrm{C}(\mathrm{COOL})$, respectively (temperature data presented in Périard et $a l^{19}$ ). Interestingly, it has been suggested that an elevated skin temperature may mediate self-paced exercise performance in the heat via changes in perception ${ }^{49}$ and through related increases in skin blood flow when the core-to-skin temperature gradient narrows, reducing central blood volume. ${ }^{50} 51$ To our knowledge, there is no published evidence to suggest that skin temperature elevations would result in such impairments during brief explosive efforts (ie, $15 \mathrm{~m}$ sprints and jumps), especially when given the opportunity to recover between bouts. Consequently, it does not appear that the lack of difference in physical performance between the HOT and COOL conditions was related to physical assessments having been performed in similarly hot ambient conditions.

\section{CONCLUSION}

The study has revealed that, after $20 \mathrm{~min}$ of effective match-play tennis ( $2 \mathrm{~h}$ total time), acute reductions occurred in the ability to perform $15 \mathrm{~m}$ repeated sprints and a $15 \mathrm{~m}$ sprint with one direction change, as well as in leg ability factors (eg, leg stiffness, SJ height). These were developed primarily by midmatch, as only small additional reductions were incurred postmatch. Interestingly, neither the time course of physical performance changes during the match nor the subsequent recovery responses (ie, complete recovery within $24 \mathrm{~h}$ ) were adversely affected when playing in a HOT $\left(36^{\circ} \mathrm{C}\right)$ compared with a $\operatorname{COOL}\left(22^{\circ} \mathrm{C}\right)$ environment. As such, it appears that competing in ambient temperatures close to that of body temperature does not exacerbate impairments in the mechanical characteristics of the muscle-tendon complex induced by prolonged match-play tennis.

\section{What are the new findings?}

- Physical performance deteriorates when playing tennis for $\sim 2 \mathrm{~h}$, as evidenced by reductions in musculoskeletal stiffness, explosive power and repeated-sprint ability.

- Impairments primarily occur at midmatch with only small additional reductions at postmatch.

- Physical performance recovers $24 \mathrm{~h}$ into recovery after play in cool and hot environmental conditions.

- Match-related fatigue and recovery responses display similar patterns between the two environments. 
How might the findings impact on clinical practice in the near future?

Resistance training strategies (eg, plyometric or eccentric regimens) may limit premature or excessive match-induced neuromuscular load imposed to the musculoskeletal system induced by tennis match-play through an upregulation of leg ability factors.

Acknowledgements The authors thank all the players for their efforts. They are very grateful to Tim Colijn and Samuel Rota for their help in implementing the protocol. They also thank the staff from Research and Education Centre (Aspetar) for their valuable assistance with data collection and statistical analyses.

Contributors OG, SR and JDP designed the study. All authors performed subject recruitment and all measurements. OG and RJC performed the statistical analyses, and all authors contributed to data interpretation. OG drafted the manuscript, and all authors critically revised the article. All authors gave final approval of the submitted manuscript.

Funding This project was funded by the Aspire Zone Foundation Research Grant. Competing interests None.

Ethics approval The study was approved by the Shafallah Medical Genetics Center Ethical Research Committee and conformed to the current Declaration of Helsinki guidelines.

Provenance and peer review Not commissioned; externally peer reviewed.

Open Access This is an Open Access article distributed in accordance with the Creative Commons Attribution Non Commercial (CC BY-NC 3.0) license, which permits others to distribute, remix, adapt, build upon this work non-commercially, and license their derivative works on different terms, provided the original work is properly cited and the use is non-commercial. See: http://creativecommons.org/ licenses/by-nc/3.0/

\section{REFERENCES}

1 Girard O, Millet GP. Neuromuscular fatigue in racquet sports. Neurol Clin 2008;26:181-94.

2 Hornery D, Farrow D, Mujika I, et al. Fatigue in tennis: mechanisms of fatigue and effect on performance. Sports Med 2007;37:199-212.

3 Mendez-Villanueva A, Fernandez-Fernandez J, Bishop D. Exercise induced homeostatic perturbations provoked by singles tennis match play with reference to development of fatigue. Br J Sports Med 2007;41:717-22.

4 Girard O, Lattier G, Micallef JP, et al. Changes in exercise characteristics, maximal voluntary contraction and explosive strength during prolonged tennis playing. $\mathrm{Br} \mathrm{J}$ Sports Med 2006;40:521-6.

5 Mitchell JB, Cole KJ, Grandjean PW, et al. The effect of a carbohydrate beverage on tennis performance and fluid balance during prolonged tennis play. J App/ Sport Sci Res 1992;6:174-80.

6 Ojala T, Häkkinen K. Effects of the Tennis tournament on players' physical performance, hormonal responses, muscle damage and recovery. J Sports Sci Med 2013;12:240-8.

7 Magal M, Webster MJ, Sistrunk LE, et al. Comparison of glycerol and water hydration regimens on tennis-related performance. Med Sci Sports Exerc 2003;35:150-6.

8 Kraemer WJ, Piorkowski PA, Bush JA, et al. The effects of NCAA Division 1 intercollegiate competitive tennis match play on recovery of physical performance in women. J Strength Cond Res 2000;14:265-72.

9 Nédelec M, McCall A, Carling C, et al. Recovery in soccer. Part I-postmatch fatigue and time course of recovery. Sports Med 2012;42:997-1015.

10 Kovacs MS. A review of fluid and hydration in competitive tennis. Int I Sports Physiol Perf 2008;3:413-23.

11 Mountjoy M, Alonso J-M, Bergeron MF, et al. Hyperthermic-related challenges in aquatics, athletics, football, tennis and triathlon. Br J Sports Med 2012;46:800-4.

12 Drust $B$, Rasmussen $\mathrm{P}$, Mohr $\mathrm{M}$, et al. Elevations in core and muscle temperature impairs repeated sprint performance. Acta Physiol Scand 2005;183:181-90.

13 Almudehki F, Girard 0, Grantham J, et al. Hot ambient conditions do not alter intermittent cycling sprint performance. J Sci Med Sport 2012;15:148-52.

14 Girard 0, Bishop DJ, Racinais S. Hot conditions improve power output during repeated cycling sprints without modifying neuromuscular fatigue characteristics. Eur J Appl Physiol 2013;113:359-69.

15 Davey $P$, Thorpe $R$, Williams C. Fatigue decreases skilled tennis performance. J Sports Sci 2002;20:311-18.
16 Fabre J-B, Martin V, Gondin J, et al. Effect of playing surface properties on neuromuscular fatigue in tennis. Med Sci Sports Exerc 2012;44:2182-9.

17 Morante $S$, Brotherhood J. Match characteristics of professional singles tennis. Med Sci Tennis 2005;10:12-13.

18 Fernandez-Fernandez J, Zimek R, Wiewelhove T, et al. High-intensity interval training vs. repeated-sprint training in tennis. J Strength Cond Res 2012;26:53-62.

19 Périard J, Racinais S, Knez WL, et al. Thermal, physiological and perceptual strain mediate alterations in match-play tennis under heat stress. Br J Sports Med 2014;48:i32-8.

20 Girard 0, Mendez-Villanueva A, Bishop D. Repeated-sprint ability-part 1. Factors contributing to fatigue. Sports Med 2011;41:673-94.

21 Lehance $C$, Croisier J-L, Bury T. Optojump system efficiency in the assessment of lower limbs axplosive strength. Sci Sports 2005;20:131-5.

22 Dalleau G, Belli A, Viale F, et al. A simple method for field measurements of leg stiffness in hopping. Int J Sports Med 2004;25:170-6.

23 Delextrat A, Baliqi F, Clarke N. Repeated sprint ability and stride kinematics are altered following an official match in national-level basketball players. J Sports Med Phys Fitness 2013:53:112-18.

24 Mohr M, Mujika I, Santisteban J, et al. Examination of fatigue development in elite soccer in a hot environment: a multi-experimental approach. Scand J Med Sci Sports 2010;20:125-32.

25 Nybo L, Girard O, Mohr M, et al. Markers of muscle damage and performance recovery after exercise in the heat. Med Sci Sports Exerc 2013;45:860-8.

26 Ferrauti A, Weber K, Struder HK. Metabolic and ergogenic effects of carbohydrate and caffeine beverages in tennis. J Sports Med Phys Fitness 1997;37:258-66.

27 Périard J, Girard 0, Racinais J. Neuromuscular adjustments of the knee extensors and plantar flexors following match-play tennis in the heat. Br J Sports Med 2014;48:i45-51.

28 Girard O, Micallef J-P, Millet GP, et al. Changes in spring-mass model characteristics during repeated running sprints. Eur J Appl Physiol 2011;111:125-34.

29 Ferrauti A, Pluim BM, Weber $K$. The effect of recovery duration on running speed and stroke quality during intermittent training drills in elite tennis players. J Sports Sci 2001;19:235-42.

30 Leone M, Comtois AS, Tremblay F, et al. Specificity of running speed and agility in competitive junior tennis players. Med Sci Tennis 2006;11:10-11.

31 Vergauwen L, Brouns F, Hespel P. Carbohydrate supplementation improves stroke performance in tennis. Med Sci Sports Exerc 1998;30:1289-95.

32 Morin JB, Edouard P, Samozino P. Technical ability of force application as a determinant factor of sprint performance. Med Sci Sports Exerc 2011;43:1680-8.

33 Brughelli $M$, Cronin J, Levin $G$, et al. Understanding change of direction ability in sport: a review of resistance training studies. Sports Med 2008;38:1045-63.

34 Markovic G. Poor relationship between strength and power qualities and agility performance. J Sports Med Phys Fitness 2007;47:276-83.

35 Bonnard M, Sirin AV, Oddsson L, et al. Different strategies to compensate for the effects of fatigue revealed by neuromuscular adaptation processes in humans. Neurosci Lett 1994;166:101-5.

36 Bobbert MF, Casius LJ. Is the effect of a countermovement on jump height due to active state development? Med Sci Sports Exerc 2005;37:440-6.

37 Robineau J, Jouaux $T$, Lacroix $M$, et al. Neuromuscular fatigue induced by a 90-minute soccer game modeling. J Strength Cond Res 2012;26:555-62.

38 Kraemer WJ, Piorkowski PA, Bush JA, et al. The effects of NCAA division 1 intercollegiate competitive tennis match play on recovery of physical performance in women. J Strength Cond Res 2000;14:265-72.

39 Girard O, Millet GP. Physical determinants of tennis performance in competitive teenage players. J Strength Cond Res 2009;23:1867-72.

40 Maquirriain J. The interaction between the tennis court and the player: how does surface affect leg stiffness? Sports Biomech 2013;1:48-53.

41 Chelly SM, Denis C. Leg power and hopping stiffness: relationship with sprint running performance. Med Sci Sports Exerc 2001;33:326-33.

42 Butler RJ, Crowel HP, Davis IM. Lower extremity stiffness: implications for performance and injury. Clin Biomech 2003;18:511-17.

43 Durand S, Ripamonti M, Beaune B, et al. Leg ability factors in tennis players. Int $J$ Sports Med 2010;31:882-6.

44 Strickler T, Malone T, Garrett WE. The effects of passive warming on muscle injury. Am J Sports Med 1990;18:141-5.

45 Warren CG, Lehmann JF, Kablanski JN. Heat and stretch procedures: an evaluation using rat tail tendon. Arch Phys Med Rehab 1976;57:122-6.

46 Sawka MN, Burke LM, Eichner ER, et al. American College of Sports Medicine position stand. Exercise and fluid replacement. Med Sci Sports Exerc 2007;39:377-90.

47 Cian C, Barraud PA, Melin B, et al. Effects of fluid ingestion on cognitive function after heat stress or exercise-induced dehydration. Int J Psychophysiol 2001;42:243-51.

48 Knicker AJ, Renshaw I, Oldham A, et al. Interactive processes link the multiple symptoms of fatigue in sport competition. Sports Med 2011;41:307-28.

49 Schlader ZJ, Simmons SE, Stannard SR, et al. Skin temperature as a thermal controller of exercise intensity. Eur J App/ Physiol 2011;111:1631-9.

50 Ely BR, Cheuvront SN, Kenefick RW, et al. Aerobic performance is degraded, despite modest hyperthermia, in hot environments. Med Sci Sports Exerc 2010;42:135-41.

51 Périard JD, Cramer MN, Chapman PG, et al. Cardiovascular strain impairs prolonged self-paced exercise in the heat. Exp Physiol 2011;96:134-44. 